\title{
A study on plastic strain accumulation caused by traveling of temperature distribution synchronizing with temperature rise
}

\author{
Satoshi OKAJIMA* \\ *Japan Atomic Energy Agency \\ 4002 Narita, Oarai, Ibaraki, 311-1393, Japan \\ E-mail: okajima.satoshi@jaea.go.jp
}

Received 15 October 2015

\begin{abstract}
The prevention of excessive deformation by thermal ratcheting is important in the design of high-temperature components of fast breeder reactors (FBR). This includes evaluation methods for a new type of thermal ratcheting caused by an axial traveling of temperature distribution, which corresponds to moving-up of liquid sodium surface in startup phase. Long range traveling of the axial temperature distribution brings flat plastic deformation profile in wide range. Therefore, at the center of this range, residual stress that brings shakedown behavior does not accumulate. As a result, repeating of this temperature traveling brings continuous accumulation of the plastic strain, even if there is no primary stress. In contrast, in the case with short range traveling, residual stress is caused by constraint against elastic part, and finally it results in shakedown. Because of this mechanism, we supposed that limit for the shakedown behavior depends on distance from the elastic part (i.e. half length of region with plastic deformation). In this paper, we examined characteristics of the accumulation of the plastic strain caused by realistic heat transients, namely, traveling of temperature distribution synchronizing with temperature rise. This examination was based on finite element analyses using elastic-perfectly plastic material. As a result, we confirmed that the shakedown limit depends not on the traveling range of the temperature distribution but the plastic deformation range, which was predicted by the elastic analysis. In the actual application, we can control the plastic deformation range by changing rate of the moving-up of liquid sodium surface.
\end{abstract}

Key words : Ratcheting, Plastic strain, Thermal stress, Traveling temperature distribution, Finite element analyses

\section{Introduction}

In designing fast reactors that use sodium as the coolant, an elevated temperature design standard that focuses on the thermal stress is required. The prevention of excessive plastic deformation due to ratcheting is one important consideration for the elevated temperature design. The most well-known ratcheting mechanism is the Bree-type ratcheting (Bree, 1967) which occurs under the combination of primary stress (such as internal pressure) and cyclic thermal stress.

The continuous accumulation of plastic strain may also be caused by axial movement of the temperature-distribution along the cylindrical structure, such as that during the thermal transient of the startup process for the reactor vessel. This ratcheting can occur under thermal stress alone, and primary stress is not required for strain accumulation. Wada et al. $(1989,1993)$ proposed the evaluation method for the plastic strain increment due to the temperature distribution traveling long ranges. Igari et al. (1990) studied the ratcheting mechanism experimentally, and confirmed the conservative nature of the method proposed by Wada et al.

The ratcheting strain depends on the traveling range of the temperature distribution, that is, accumulation of the ratcheting strain derived from short range traveling of the temperature distribution saturates at early stage. Igari et al. (2000) proposed the mechanism-based evaluation method to evaluate the thermal ratcheting due to the temperature distribution traveling not only long range but also short range. In the "hot-spot model" used in their formulation, the 
range in which the plastic strain accumulates is equivalent to the traveling range of the temperature distribution.

We proposed a screening method of thermal ratcheting strain due to the short range traveling in the previous paper (Okajima et al., 2014). In the previous paper, we focused not on the traveling range of the temperature distribution but an axial length of the plastic deformation area. Based on a set of elasto-plastic finite element analyses, we validated applicability of the proposed method to the lamp-shape temperature distribution simulating that nearby the liquid sodium surface. In this validation, the shape of the temperature distribution was assumed as constant in the traveling phase.

In actual process of the FBR startup, without any conscious control, the increasing of the coolant level is synchronizing with the increasing of the coolant temperature. This synchronizing transient brings smaller plastic deformation area than the transient used in the usual papers (Igari et al., 2000)(Okajima et al., 2014).

In this paper, we studied characteristics of the accumulation of the plastic strain caused by traveling of temperature distribution synchronizing with temperature rise. This study was based on finite element analyses using elastic-perfectly plastic material.

\section{Prevention method for thermal ratcheting strain caused by the traveling temperature distribution 2.1 Mechanism of the thermal ratcheting}

At start-up phase of fast reactors that use sodium as the coolant, large change of the coolant temperature occurs. Due to high heat transfer coefficient between the liquid sodium and the vessel wall, a sharp axial temperature gradient is generated on the vessel wall near the liquid sodium surface. Meanwhile, the temperature change of the coolant brings thermal expansion of the coolant that result in increasing of coolant level. Increasing the liquid sodium level causes the temperature distribution to move along the vessel wall.
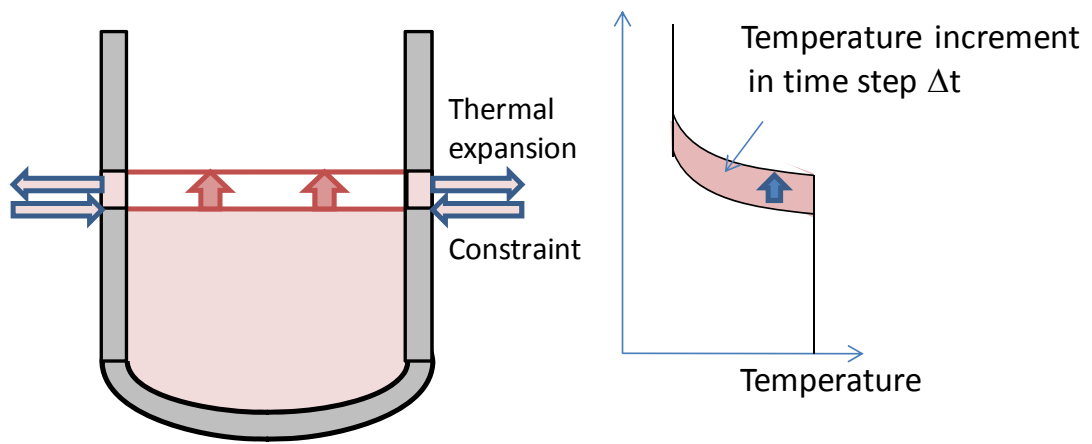

Fig.1 The traveling temperature model of the reactor vessel near the liquid sodium surface

Figure 1 shows the traveling temperature model of the reactor vessel near the liquid sodium surface at the start-up phase. In a short time step, the temperature distribution on the vessel wall changes only in the narrow range near the liquid surface. In this narrow range, since there is constraint against the section of wall where the temperature has not changed, almost all of the thermal expansion from the temperature change is exchanged into the elastic and plastic compressive strain in the circumferential direction. Meanwhile, in surrounding region, tensile strain is caused by the thermal expansion in the narrow range with temperature change. Because of difference of rigidity, the compressive strain caused in the range with the temperature change is larger than the tensile strain caused in the surrounding region.

With a long range traveling temperature distribution, a large plastic deformation region is generated. In the center of the plastic region, spatially uniform plastic strain accumulates, and there is no residual stress after the temperature distribution has moved. In this case, because the residual stress that brings shakedown behavior does not accumulate, the plastic strain accumulates each cycle. Therefore, the lack of residual stress accumulation is the main mechanism of ratcheting due to the long traveling temperature distribution.

When the traveling range of the temperature distribution is short, constraint against the elastic part causes residual stress to accumulate (even occurs in the middle of the traveling range), as shown in Fig. 2. The magnitude of the residual stress depends on the distance from the elastic part (i.e. the traveling range of the temperature distribution). The residual stress decreases the ratcheting strain increment in the following cycles. With the sufficient constraint against the elastic part, the residual stress increases with transient cycles, until finally shakedown occurs. 


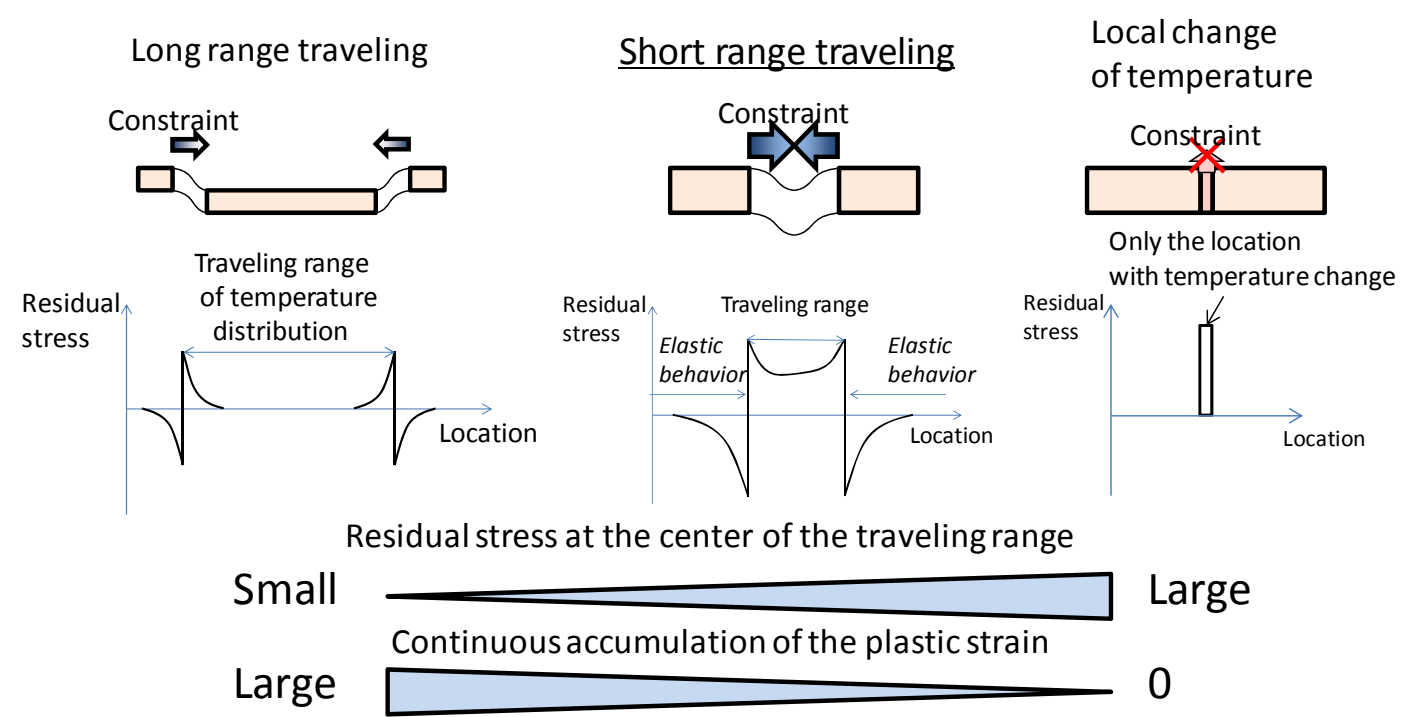

Fig.2 Comparison of residual stress distributions for different traveling ranges

\subsection{Mechanism-based evaluation method (Igari et al., 2000)}

Igari et al. (2000) formulated the residual stress based on the Timoshenko's shell theory (Timoshenko and Krieger, 1959), using hot-spot model consisting of very short region on the cylinder with hot temperature and the residual cold part. This hot-spot-shape temperature distribution causes compressive plastic strain in very short region and compressive thermal membrane stress in the residual part.

In the case when this temperature distribution moves on axial direction, plastic deformation is caused in an entire part passed through by the temperature distribution. When the residual stress in part that is not passed through the temperature distribution reaches the yield strength, part with the plastic deformation expands and the constraint against elastic part is reduced. Because of this reason, Igari et al. explained that shakedown occurs when yielding does not occur at start and end point of the temperature distribution movement.

\subsection{Screening criteria proposed in the previous study (Okajima et al., 2014)}

In the previous paper (Okajima et al., 2014), we proposed a screening method of thermal ratcheting strain for practical components design. The proposed method initially determines whether plastic deformation occurs at all points through the wall thickness. If all points of certain cross-section are in the plastic state, the proposed method determines whether the plastic strain saturates based on axial length of the plastic deformation area, $l_{p}$. To prevent the continuous accumulation of the plastic strain, we required to satisfy Eq.(1) in the previous paper. Equation (1) was validated by a set of finite element analyses using elastic perfectly plastic material.

$$
\beta l_{p} \leq 0.93
$$

where $\beta$ is Timoshenko's shell parameter (Timoshenko and Krieger, 1959), which can be obtained by Eq.(2).

$$
\beta=\frac{\sqrt[4]{3\left(1-v^{2}\right)}}{\sqrt{r \cdot t}}
$$

where $r$ and $t$ are inner radius and thickness of the cylinder. $v$ is Poisson's ratio of the cylinder material.

\section{Analytical study}

\subsection{Conditions and procedures}

\subsubsection{Heat transfer analysis}

To study feature of the plastic strain accumulation, we carried out a series of finite element analyses for the model 
with traveling of temperature distribution synchronizing with temperature rise. The analyses series consist of 2 types of analyses: heat-transfer analyses and structure analyses. Conditions used in these analyses are shown in this section. The FEM code and element used in these analyses were FINAS (Iwata et al., 1982) Ver.21 and the 8-node axisymmetric solid element, respectively.

At first, we carried out heat transfer analysis to obtain temperature response against the heat transient that imitates transient in startup and shutdown processes. Figure 3 shows the heat transients used in the case whose increase rate of the coolant level are $20 \mathrm{~mm} /$ hour and $25 \mathrm{~mm} /$ hour, as the example of the heat transient. In other cases, we used similar heat transient corresponding to the level increase rate. At the end of the startup and shutdown transient (that is 100 and 200 hour in Fig. 3 a)), we carried out steady heat conduction analyses.

Figure 4 shows comparison of assumed heat transient between this paper and the conventional studies (Igari et al., 2000)(Okajima et al., 2014). Because the traveling of the coolant level is results of the change of the coolant temperature, without any conscious control, the increasing of the coolant level is synchronizing with the increasing of the coolant temperature as shown as Fig.4 (a). In this paper, we assumed this type of heat transients.

In spite of the above mechanism, simplified heat transients are used in the conventional studies (Igari et al., 2000)(Okajima et al., 2014). These simplified transients are characterized by increasing of the coolant level after increasing of the coolant temperature, as shown as Fig.4 (b). In these simplified transient models, maximum thermal stress is caused on the entire traveling range of the coolant surface that results in larger plastic strain. That is to say, the conventional studies have been used the heat transient with the conservative assumption.

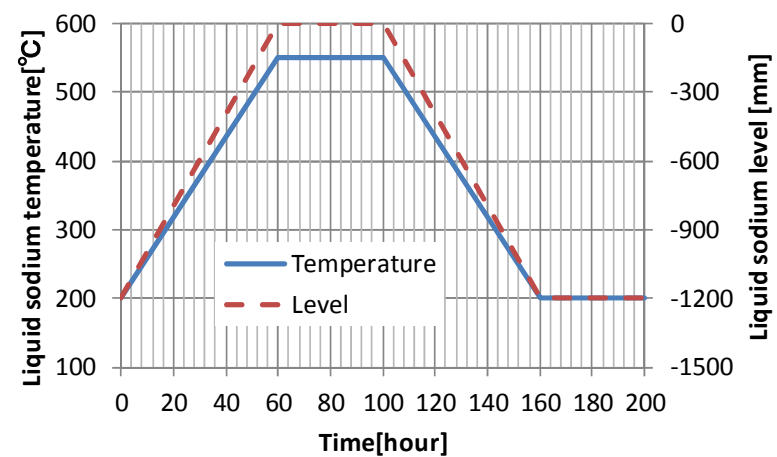

a) Increase rate of the coolant level is $20 \mathrm{~mm} /$ hour

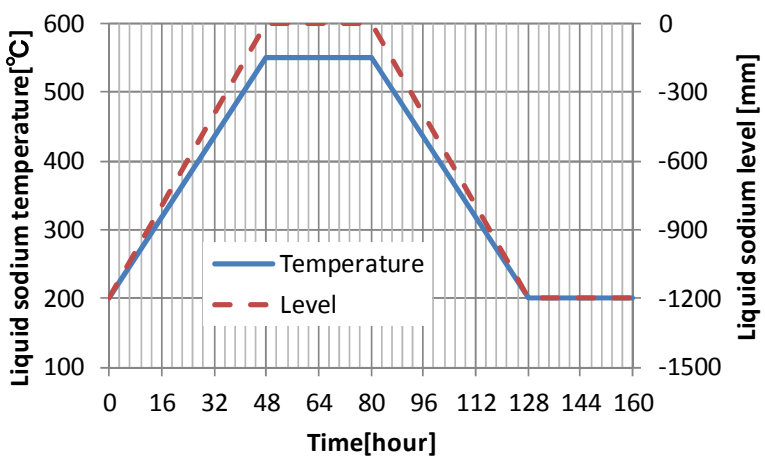

b) Increase rate of the coolant level is $25 \mathrm{~mm} /$ hour

Fig. 3 Sample of heat transient used in the analyses

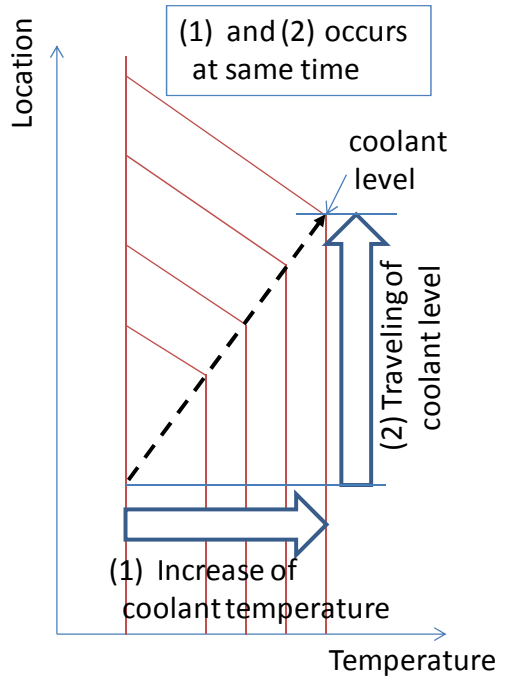

(a) This paper

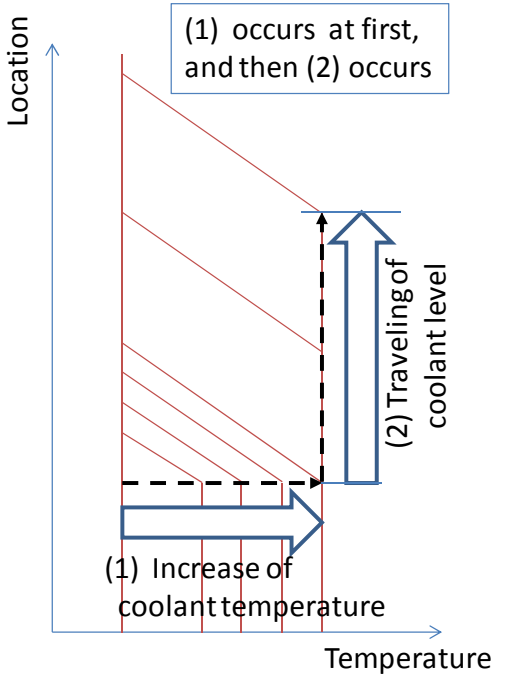

(b) Conventional study

Fig.4 Comparison of assumed heat transient between this paper and conventional study 


\subsubsection{Structural analysis}

After the heat transfer analysis, we carried out structural analyses. In these analyses, we used the temperature distribution evaluated by the heat transfer analysis as input data.

In the structural analyses, we carried out elastic analyses to obtain the axial length of the plastic deformation area, $l_{p}$, at first. We predicted $l_{p}$ as the length of the area in which Eq. (3) is satisfied, that is, as the length of the area in which the membrane stress intensity exceed yield stress.

$$
\left\langle P_{m}+Q_{m}\right\rangle_{\max }>S_{y h}
$$

where $P_{m}$ and $Q_{m}$ are Primary and Secondary membrane stress. $<>_{\max }$ denotes maximum value of stress intensity. $S_{y h}$ is yield stress associated with the higher wall averaged temperature for the stress extremes defining the secondary stress range.

After the elastic analysis, we carried out inelastic finite element analysis assuming elastic-perfectly plastic material, which is often assumed in the design evaluation process. To simulate elastic-perfectly plastic material, we defined strain-hardening coefficient as one-thousandth of the Young modulus.

\subsubsection{Conditions of the finite element analysis}

Figure 5 shows boundary conditions used in the heat-transfer and the structural analyses. Table 1 shows physical properties used in these analyses. We defined properties as the value for $316 \mathrm{FR}$ stainless steel on $550^{\circ} \mathrm{C}$.

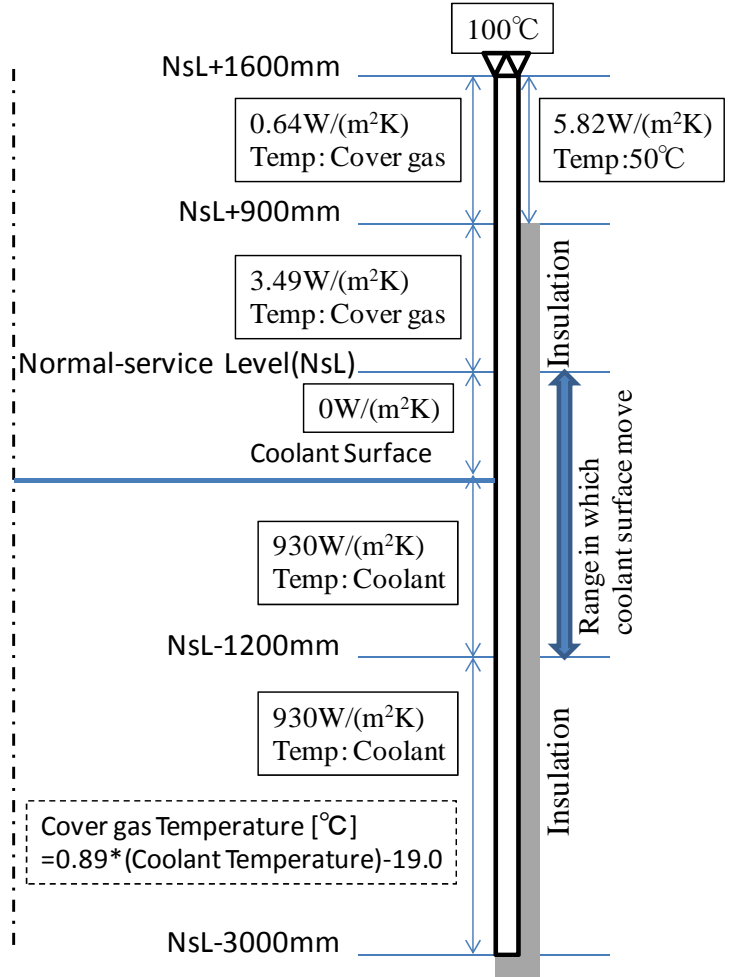

a) Heat-transfer analysis

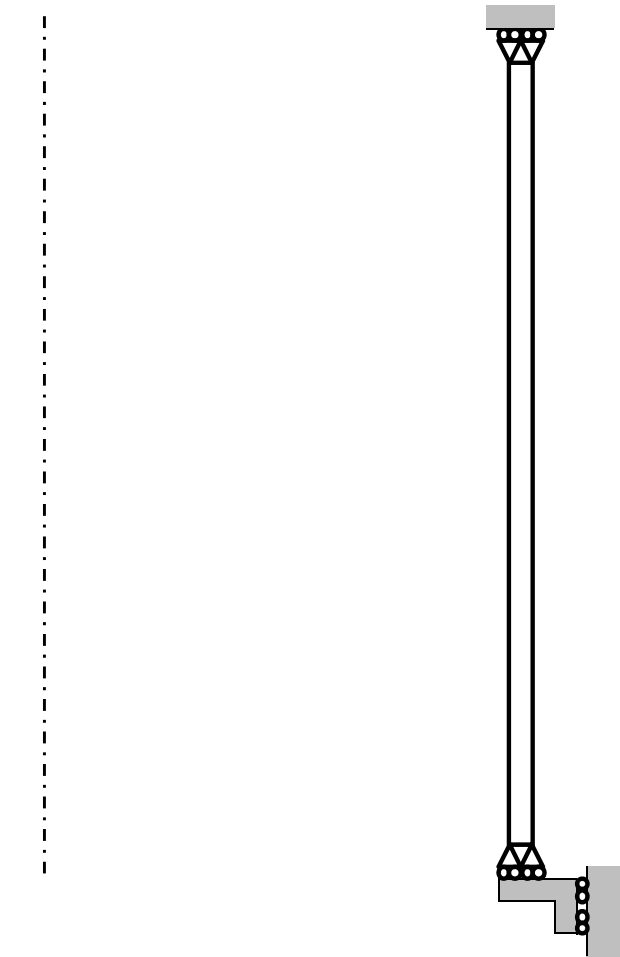

b) Structural analysis

Fig. 5 Boundary conditions used in the analyses

Table 2 shows the cases evaluated in this study. In all cases, lengths of the increasing of the coolant level are same value, $1200 \mathrm{~mm}$. Meanwhile, in order to study the cases with various value of the length of plastic deformation area, we varied increase rates of the coolant level and temperature. We used 20, 25, and 30mm/hour as the increase rate of the level. In addition, we planned to investigate 3 types of effects: effect of temperature dependency of the yield stress, effect of primary stress due to weight load and internal pressure, and thickness ratio of the reactor vessel. 
Table 1 Properties used in the analyses (JNC, 2005)

\begin{tabular}{|l|c|}
\hline Thermal conductivity of the vessel $[\mathrm{W} /(\mathrm{m} \cdot \mathrm{K})]$ & 23.0 \\
\hline Specific heat $[\mathrm{J} /(\mathrm{kg} \cdot \mathrm{K})]$ & $5.72 * 10^{2}$ \\
\hline Density $\left[\mathrm{kg} / \mathrm{m}^{3}\right]$ & $7.97 * 10^{3}$ \\
\hline \hline Young Modulus, $E[\mathrm{MPa}]$ & 154000 \\
\hline Poisson Ratio, $v$ & 0.306 \\
\hline Thermal Expansion Coefficient, $\alpha[\mathrm{mm} / \mathrm{mm}]$ & $20.64 * 10^{-6}$ \\
\hline
\end{tabular}

Table 2 Evaluated cases in the validation

\begin{tabular}{|c|c|c|c|c|c|c|}
\hline & \multicolumn{2}{|c|}{ Increase rate } & \multirow{2}{*}{ Yield stress } & \multirow{2}{*}{ Primary stress } & \multirow{2}{*}{$\begin{array}{c}\text { Radius } \\
{[\mathrm{mm}]}\end{array}$} & \multirow{2}{*}{$\begin{array}{c}\text { Thickness } \\
\text { [mm] }\end{array}$} \\
\hline & Level [mm/h] & Temperature [K/h] & & & & \\
\hline L-20 & 20 & 5.83 & \multirow{3}{*}{$\begin{array}{l}\text { Constant } \\
(105 \mathrm{MPa})\end{array}$} & \multirow[t]{6}{*}{0} & \multirow[t]{6}{*}{ "5350 } & \multirow[t]{6}{*}{60} \\
\hline L-25 & 25 & 7.29 & & & & \\
\hline L-30 & 30 & 8.75 & & & & \\
\hline CL-20 & 20 & 5.83 & \multirow{3}{*}{$\begin{array}{l}\text { Depend on } \\
\text { temperature }\end{array}$} & & & \\
\hline CL-25 & 25 & 7.29 & & & & \\
\hline CL-30 & 30 & 8.75 & & & & \\
\hline PL-20 & 20 & 5.83 & \multirow{3}{*}{$\begin{array}{l}\text { Constant } \\
(105 \mathrm{MPa})\end{array}$} & \multirow{6}{*}{$\begin{array}{l}\text { Internal } \\
\text { Preessure } \\
0.15 \mathrm{MPa} \\
\text { Axial tensile } \\
18.95 \mathrm{MPa}\end{array}$} & \multirow[t]{6}{*}{5350} & \multirow[t]{6}{*}{60} \\
\hline PL-25 & 25 & 7.29 & & & & \\
\hline PL-30 & 30 & 8.75 & & & & \\
\hline PCL-20 & 20 & 5.83 & \multirow{3}{*}{$\begin{array}{l}\text { Depend on } \\
\text { temperature }\end{array}$} & & & \\
\hline PCL-25 & 25 & 7.29 & & & & \\
\hline PCL-30 & 30 & 8.75 & & & & \\
\hline TL-20 & 20 & 5.83 & \multirow{3}{*}{$\begin{array}{l}\text { Constant } \\
(105 \mathrm{MPa})\end{array}$} & \multirow[t]{6}{*}{0} & \multirow[t]{6}{*}{2675} & \multirow[t]{6}{*}{120} \\
\hline TL-25 & 25 & 7.29 & & & & \\
\hline TL-30 & 30 & 8.75 & & & & \\
\hline TCL-20 & 20 & 5.83 & \multirow{3}{*}{$\begin{array}{l}\text { Depend on } \\
\text { temperature }\end{array}$} & & & \\
\hline TCL-25 & 25 & 7.29 & & & & \\
\hline TCL-30 & 30 & 8.75 & & & & \\
\hline
\end{tabular}

\subsection{Results}

\subsubsection{Heat transfer analyses}

Figure 6 shows the analyzed temperature distributions on the vessel wall when the increasing of the coolant level finishes in cases L-20, L-25, and L-30, which are defined in Table 2. As shown in Table 2, numerical values in the case name indicate the increase rate of the coolant level. Larger increasing rate of the coolant level brings sharper temperature gradient nearby the coolant surface, which brings larger thermal stress on circumferential direction.

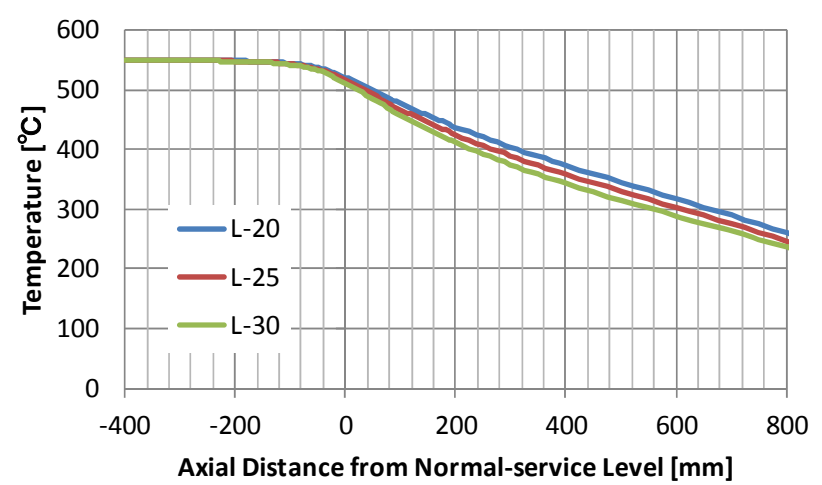

Fig. 6 Comparison of the analyzed temperature distributions 


\subsubsection{Elastic analyses}

Figure 7 shows maximum and minimum value of the circumferential stress in the transient cycle, which is evaluated by the elastic analyses. Larger increasing rate of the coolant level brings larger thermal stress on circumferential direction. In case L-30, whose increase rate is large, thermal stress reaches yield stress earlier than case L-20. Therefore, case L-30 has larger $l_{p}$ than case L-20. Because of this mechanism, although there is limitation, we can control $l_{p}$ by changing increase rate of the coolant temperature and level.

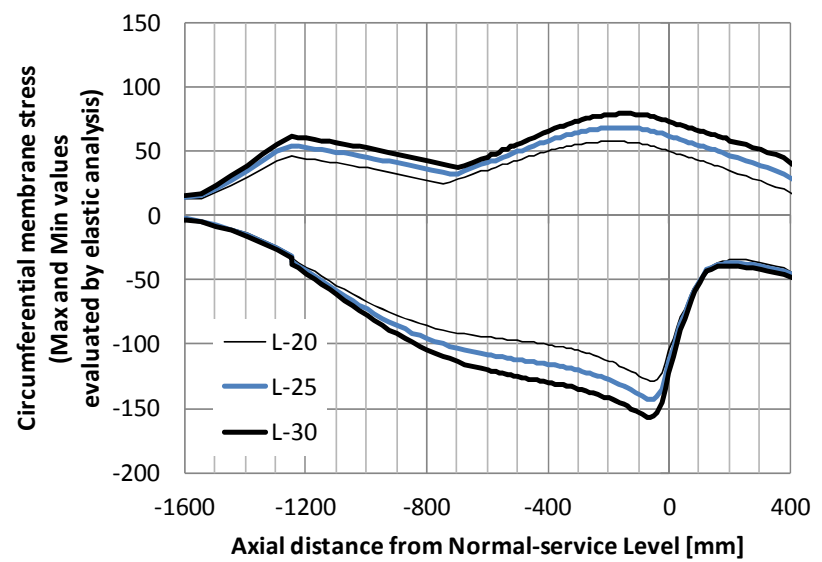

Fig. 7 Comparison of the evaluated thermal stress

Table 3 shows results of the elastic structure analyses. In Table $3,<>_{\mathrm{R}}$ denotes range of stress intensity, and $\beta$ is Timoshenko's shell parameter that is obtained by Eq.(2). In the case with consideration of the temperature dependency, the yield stress at intermediate points in the traveling range become larger. As the result, length of the plastic deformation area, $l_{p}$, become smaller. The value of $l_{p}$ in the case CL-25 was nearly equal to maximum value that satisfy Eq.(1).

Table 3 Results of the elastic analyses

\begin{tabular}{|c|c|c|c|c|c|}
\hline & $\begin{array}{c}<P_{m}+Q_{m}>_{\max } \\
{[\mathrm{MPa}]}\end{array}$ & $\begin{array}{c}<P_{m}+Q_{m}>_{\mathrm{R}} \\
{[\mathrm{MPa}]}\end{array}$ & Yield stress & $l_{p}[\mathrm{~mm}]$ & $\beta l_{p}[-]$ \\
\hline L-20 & 129 & 184 & \multirow{3}{*}{$\begin{array}{l}\text { Constant } \\
\text { (105MPa) }\end{array}$} & 300 & 0.69 \\
\hline L-25 & 143 & 209 & & 685 & 1.56 \\
\hline L-30 & 157 & 234 & & 800 & 1.84 \\
\hline CL-20 & 129 & 184 & \multirow{3}{*}{$\begin{array}{l}\text { Depend on } \\
\text { temperature }\end{array}$} & 250 & 0.58 \\
\hline CL-25 & 143 & 209 & & 425 & 0.97 \\
\hline CL-30 & 157 & 234 & & 575 & 1.29 \\
\hline PL-20 & 126 & 184 & \multirow{3}{*}{$\begin{array}{l}\text { Constant } \\
\text { (105MPa) }\end{array}$} & 265 & 0.59 \\
\hline PL-25 & 140 & 209 & & 635 & 1.44 \\
\hline PL-30 & 154 & 234 & & 775 & 1.78 \\
\hline PCL-20 & 126 & 184 & \multirow{3}{*}{$\begin{array}{l}\text { Depend on } \\
\text { temperature }\end{array}$} & 225 & 0.51 \\
\hline PCL-25 & 140 & 209 & & 410 & 0.92 \\
\hline PCL-30 & 154 & 234 & & 495 & 1.18 \\
\hline TL-20 & 131 & 187 & \multirow{3}{*}{$\begin{array}{l}\text { Constant } \\
\text { (105MPa) }\end{array}$} & 421 & 0.95 \\
\hline TL-25 & 146 & 213 & & 648 & 1.47 \\
\hline TL-30 & 160 & 236 & & 753 & 1.71 \\
\hline TCL-20 & 131 & 187 & \multirow{3}{*}{$\begin{array}{l}\text { Depend on } \\
\text { temperature }\end{array}$} & 340 & 0.77 \\
\hline TCL-25 & 146 & 213 & & 446 & 1.01 \\
\hline TCL-30 & 160 & 236 & & 543 & 1.23 \\
\hline
\end{tabular}




\subsubsection{Inelastic analyses}

Figure 8 shows axial distributions of the accumulated plastic strain on the circumferential direction evaluated by the analyses with elastic-perfectly plastic material. In the case L-20, whose increase rate is small, the accumulation of the circumferential plastic strain was quickly saturated. On the other hand, in the case L-30, whose increase rate is large, the circumferential plastic strain accumulated continuously.

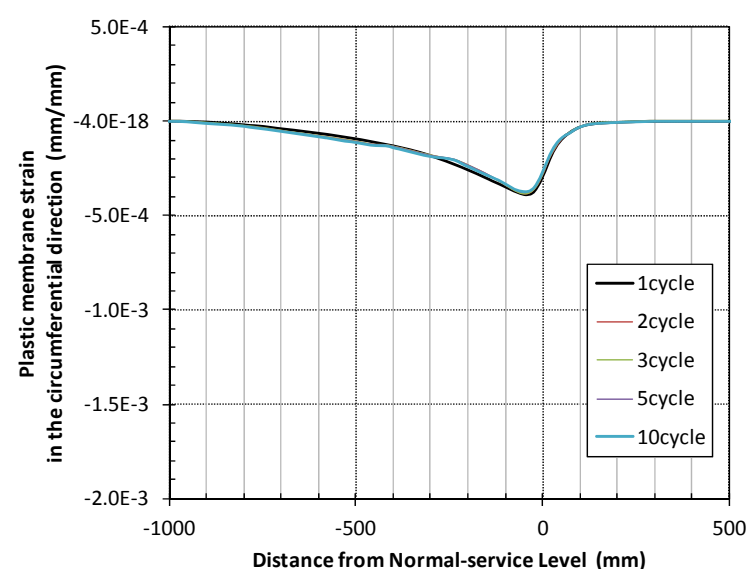

(a) Case L-20 (Increase rate is $20 \mathrm{~mm} / \mathrm{hour}$ )

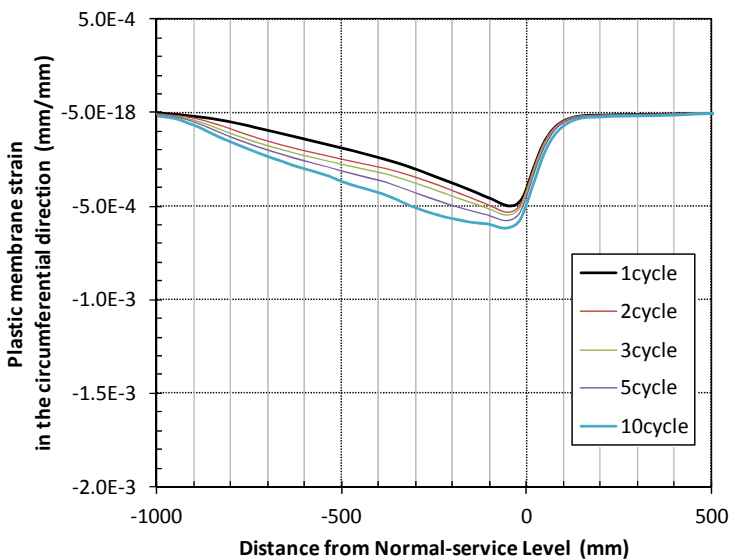

(b) Case L-25(Increase rate is $25 \mathrm{~mm} /$ hour)

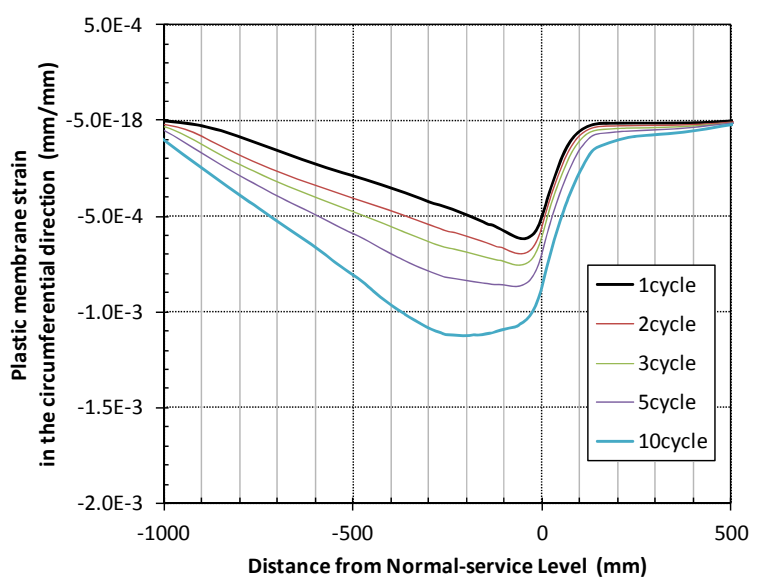

(c) Case L-30

Fig. 8 Accumulation of the circumferential plastic strain

Table 4 shows the results of the inelastic finite element analyses. In the Table 4, values of the accumulated plastic strain at the end of the 1st and 10th cycles of the heat transient are shown.

In order to study whether the plastic strain accumulates even after 2nd cycle, we focused on the ratio of plastic strain at 10th cycle to that at 1st cycle. In the case when this ratio is larger than 1 , the plastic strain accumulates even after 2nd cycle. Figure 9 shows relation between this ratio of the circumferential plastic strain and $\beta l_{p}$. $\beta$ is Timoshenko's shell parameter that is obtained by Eq.(2). $l_{p}$ is the axial length of the plastic deformation area that is obtained in 3.1.2.

As shown in Fig.9, regardless of the existence of the primary stress, the temperature dependency of the yield stress, and the radius/thickness ratio of the reactor vessel, the ratio of circumferential plastic strain depends on $\beta l_{p}$. Therefore, we proved $\beta l_{p}$ to be dominant parameter for the saturation of the plastic strain accumulation. In the cases when $\beta l_{p}$ is smaller than about 1.3, significant circumferential plastic strain did not increase after 2nd cycle. Therefore, we confirmed that the proposed criteria in the previous paper (Okajima et al., 2014), which require that $\beta l_{p}$ is smaller than 0.93 as shown in Eq.(1), prevents continuous accumulation of the plastic strain with reasonable margin, even in the case with the synchronizing increase of coolant temperature and level. 
In spite of ratcheting mechanism shown in section 2, which brings circumferential plastic strain, axial plastic strain was accumulated continuously in cases PL-25 and PL-30. As shown in Table $\left.3,<P_{m}+Q_{m}\right\rangle_{\mathrm{R}}$ was nearly equal to shakedown range $(105 * 2=210 \mathrm{MPa})$ in case PL-25, and it exceeded shakedown range in case PL-30. Therefore, we thought that the accumulation of the axial plastic strain in cases PL-25 and PL-30 was derived from excessive thermal stress range. The proposed method in the previous paper (Okajima et al., 2014) assumed the membrane stress range below the shakedown range.

Table 4 Results of the inelastic analyses

\begin{tabular}{|c|c|c|c|c|c|c|}
\hline & \multirow{3}{*}{$l_{p}[\mathrm{~mm}]$} & \multirow{3}{*}{$\beta l_{p}[-]$} & \multicolumn{4}{|c|}{ Accumulated Plastic Strain (Spatial Maximum, $10^{-4} \mathrm{~mm} / \mathrm{mm}$ ) } \\
\hline & & & \multicolumn{2}{|c|}{ Circumferential } & \multicolumn{2}{|c|}{ Axial } \\
\hline & & & $1^{\mathrm{st}}$ & $10^{\text {th }}$ & $1^{\text {st }}$ & $10^{\text {th }}$ \\
\hline $\mathrm{L}-20$ & 300 & 0.69 & -3.9 & -3.7 & 1.9 & 2.7 \\
\hline L-25 & 685 & 1.56 & -5.0 & -6.1 & 2.4 & 3.8 \\
\hline L-30 & 800 & 1.84 & -6.2 & -11.3 & 2.9 & 5.4 \\
\hline CL-20 & 250 & 0.58 & -3.9 & -3.6 & 2.0 & 2.5 \\
\hline CL-25 & 425 & 0.97 & -5.1 & -4.8 & 2.6 & 3.0 \\
\hline CL-30 & 575 & 1.29 & -6.3 & -7.0 & 3.2 & 4.0 \\
\hline PL-20 & 265 & 0.59 & -3.5 & -3.0 & 3.5 & 6.1 \\
\hline PL-25 & 635 & 1.44 & -4.6 & -5.0 & 4.1 & 11.2 \\
\hline PL-30 & 775 & 1.78 & -5.8 & -9.8 & 4.7 & 21.5 \\
\hline PCL-20 & 225 & 0.51 & -3.7 & -3.4 & 3.7 & 4.9 \\
\hline PCL-25 & 410 & 0.92 & -4.8 & -4.2 & 4.3 & 6.1 \\
\hline PCL-30 & 495 & 1.18 & -6.0 & -6.0 & 5.0 & 8.3 \\
\hline TL-20 & 421 & 0.95 & -4.5 & -4.5 & 1.9 & 2.4 \\
\hline TL-25 & 648 & 1.47 & -5.6 & -7.4 & 2.4 & 3.5 \\
\hline TL-30 & 753 & 1.71 & -6.7 & -12.0 & 3.0 & 4.5 \\
\hline TCL-20 & 340 & 0.77 & -4.4 & -3.9 & 1.9 & 2.0 \\
\hline TCL-25 & 446 & 1.01 & -5.7 & -5.7 & 2.5 & 2.9 \\
\hline TCL-30 & 543 & 1.23 & -7.0 & -8.0 & 3.2 & 4.0 \\
\hline
\end{tabular}

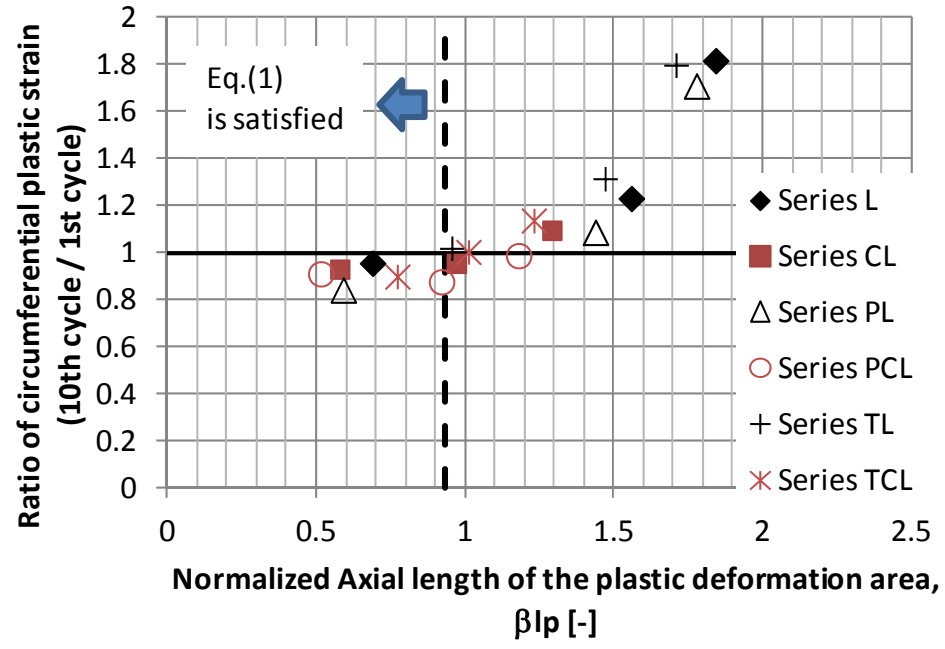

Fig. 9 Relation between ratio of the accumulated plastic strain and the length of the plastic deformation area

\section{Conclusions}

In this paper, we studied characteristics of the accumulation of the plastic strain caused by traveling of temperature distribution synchronizing with temperature rise. This study was based on finite element analyses using elastic-perfectly plastic material.

As a result, we confirmed that the saturation of the plastic strain accumulation depends not on the traveling range 
of the temperature distribution but the plastic deformation range, which was predicted by the elastic analysis. Additionally, in the cases when $\beta l_{p}$ is smaller than about 1.3, significant circumferential plastic strain did not increase after 2nd cycle. Therefore, we confirmed that the proposed criteria in the previous paper (Okajima et al., 2014), which is formulated as Eq.(1), prevents continuous accumulation of the plastic strain with reasonable margin. In the actual application, we can control the plastic deformation range by increasing rate of the liquid level.

\section{Acknowledge}

We express our gratitude to Takashi Wakai and Nobuchika Kawasaki for their useful discussion about interpretation of the results of analyses.

\section{References}

Bree, J., Elastic Plastic Behavior of Thin Tubes Subjected to Internal Pressure and Intermittent High Heat Fluxes with Application to Fast Nuclear Reactor Fuel Elements, J. Strain Anal., Vol.2 (1967), pp.226-238.

Igari, T., Ymauchi, M., Kitade, S., Kawasaki, K., Wada, H., Kamishima, Y., Ratcheting Behavior of a Cylinder Subjected to Thermal Stress Alone, Transaction of Japan Society of Mechanical Engineers, Series A, Vol.56 (1990), pp.1217-1225 (in Japanese).

Igari, T., Wada, H., Ueta, M., Mechanism-Based Evaluation of Thermal Ratcheting due to Traveling Temperature Distribution, J. Pressure Vessel Technol. Vol.122, No.2 (2000), pp.130-138.

Iwata, K., Kano, T., Atsumo, H. and Takeda, H., General Purpose Nonlinear Analysis Program FINAS for Elevated Temperature Design of FBR Components, Benchmark Problem Studies and Piping Systems at Elevated Temperature, PVP- Vol.66 (1982), ASME, pp.119-137.

Japan Nuclear Cycle Development Institute (JNC), The Japan Atomic Power Company, Study on Advanced Structural Design for Commercialized Fast Breeder Reactors, JNC TY9400 2005-012-2(2005).

Okajima, S., Wakai, T., Ando, M., Inoue, Y., Watanabe, S., Proposal of the Screening Method for Prevention of the Accumulation of the Ratcheting Strain Derived from the Movement of the Temperature Distribution, Proceeding of ASME 2014 Pressure Vessels and Piping Conference (2014), Paper No. PVP2014-28875.

Timoshenko, S., Krieger, S. W., Theory of Plates and Shells (1959), McGraw-Hill.

Wada, H., Igari, T., Kitade, S., Prediction Method for Thermal Ratcheting of a Cylinder Subjected to Axially Moving Temperature Distribution, Transaction of Japan Society of Mechanical Engineers, Series A, Vol.55 (1989), pp.985-993 (in Japanese).

Wada, H., Kaguchi, H., Ueta, M., Ichiyama, M., Kimura, K., Fukuda, Y., Suzuki, M., Proposal of a New Estimation Method for the Thermal Ratcheting of a Cylinder Subjected to a Moving Temperature Distribution, Nuclear Engineering and Design, Vol. 139 (1993), pp.261-267. 